\title{
ERP correlates of word production predictors in picture naming: a trial by trial multiple regression analysis from stimulus onset to response
}

\section{Andrea Valente *, Audrey Bürki and Marina Laganaro}

Faculté de Psychologie et des Sciences de l'Éducation, University of Geneva, Geneva, Switzerland

\section{Edited by:}

Thomas J. Grabowski, University of Washington School of Medicine, USA

\section{Reviewed by:}

Tal Yarkoni, University of Colorado Boulder, USA

Gwen Alexandra Frishkoff, Georgia State University, USA

William W. Graves, Rutgers

University, USA

\section{*Correspondence:}

Andrea Valente, Laboratoire de Psychologie Cognitive, Aix-Marseille Université, 3 Place Victor Hugo, 13331 Marseille, France e-mail: valentea78@gmail.com
A major effort in cognitive neuroscience of language is to define the temporal and spatial characteristics of the core cognitive processes involved in word production. One approach consists in studying the effects of linguistic and pre-linguistic variables in picture naming tasks. So far, studies have analyzed event-related potentials (ERPs) during word production by examining one or two variables with factorial designs. Here we extended this approach by investigating simultaneously the effects of multiple theoretical relevant predictors in a picture naming task. High density EEG was recorded on 31 participants during overt naming of 100 pictures. ERPs were extracted on a trial by trial basis from picture onset to $100 \mathrm{~ms}$ before the onset of articulation. Mixed-effects regression models were conducted to examine which variables affected production latencies and the duration of periods of stable electrophysiological patterns (topographic maps). Results revealed an effect of a pre-linguistic variable, visual complexity, on an early period of stable electric field at scalp, from 140 to $180 \mathrm{~ms}$ after picture presentation, a result consistent with the proposal that this time period is associated with visual object recognition processes. Three other variables, word Age of Acquisition, Name Agreement, and Image Agreement influenced response latencies and modulated ERPs from $\sim 380 \mathrm{~ms}$ to the end of the analyzed period. These results demonstrate that a topographic analysis fitted into the single trial ERPs and covering the entire processing period allows one to associate the cost generated by psycholinguistic variables to the duration of specific stable electrophysiological processes and to pinpoint the precise time-course of multiple word production predictors at once.

Keywords: ERP, topographies, single trial, picture naming, encoding processes

\section{INTRODUCTION}

The representations and processes underlying word processing for speech production have been studied extensively for more than three decades with various experimental approaches, including the analysis of speech errors (e.g., Fromkin, 1971; Garrett, 1980; Dell, 1990), chronometric paradigms (Bock, 1996), eye movements studies (e.g., Griffin, 2001), and event-related potential (ERP) approaches (Ganushchak et al., 2011). In language production research, one of the main endeavors has been to unveil the properties and time course of the encoding stages involved in producing a word. Most chronometric studies involve picture naming tasks where the dependent variable is the time interval between picture presentation and the onset of articulation (see Johnson et al., 1996 for a review). In many of these picture naming experiments, the properties of the words (e.g., frequency, age of acquisition, length) or of the pictures (e.g., visual complexity) are manipulated. On the basis of the influence that such properties exert on picture naming latencies relative to their influence on response times in other tasks (e.g., word-picture matching, Jescheniak and Levelt, 1994), inferences are drawn on the organization of words in memory and/or on the processes underlying their production. Within the framework of chronometric approaches, eye movements studies have provided information on the relation between gaze and the planning and execution of utterances, allowing to pinpoint the time course of the encoding stages involved in word production (e.g., Meyer et al., 1998; Griffin, 2001).

More recently, ERP studies have begun to examine which time periods are modulated by specific psycholinguistic variables, in order to associate these effects with the time course of underlying encoding processes. Both approaches have specific limitations due to methodological constraints. On the one hand, behavioral chronometric methods allow the investigation of several relevant variables simultaneously, but the precise time course of their effects can only be inferred by summoning the results of different studies (e.g., Alario et al., 2004). On the other hand, ERP studies allow insight into the time periods affected by specific variables, but usually investigated a few variables at a time (e.g., Cheng et al., 2010; Strijkers et al., 2010).

A more indirect contribution to this debate is provided by studies associating behavioral techniques and functional magnetic resonance imaging (fMRI) with the purpose of mapping the neural substrates of the processing stages involved in word production (e.g., Graves et al., 2007; Wilson et al., 2009). However, 
fMRI technique lacks the precise temporal resolution provided by EEG and ERPs.

The present research provides a novel and complementary approach by investigating simultaneously the effects of multiple theoretically relevant psycholinguistic variables on ERPs covering the entire word encoding period from picture onset to articulation. We expect that this approach will provide new information on the temporal characterization of the encoding stages involved in word production from presentation of the picture to the articulation of the corresponding word.

In the following section we will briefly review the psycholinguistic approaches and ERP studies that have examined the time course of word encoding, before describing the approach of the present study.

Models of word production agree on the fact that speakers have to go through a sequence of three major cognitive processes before they can articulate the name corresponding to a picture (e.g., Glaser, 1992; Levelt et al., 1999), although different claims are made regarding the dynamics of these encoding processes (Dell, $1986,1988)$. The first process involves visual processing and leads to object recognition. The second process involves the activation of the corresponding concept. It is only at the third processing stage that language gets involved, with the encoding of the corresponding word. This step, often referred to as the formulation process (e.g., Levelt et al., 1999) has been extensively detailed in the psycholinguistic literature and is assumed to entail several processing sub-stages: lexical selection, phonological encoding, and phonetic encoding. Lexical selection corresponds to the retrieval from the mental lexicon of a lemma, i.e., a semantically and syntactically specified representation (lexical-semantic processes). The word's phonological representation or lexeme is specified during phonological encoding (lexical-phonological processes); then, on the basis of the abstract phonological codes, syllable-sized articulatory gestures and their temporal relationships are either computed or retrieved (phonetic encoding) before articulation can start. The average time needed to start articulating a word from picture onset is less than a second. More recently, a major effort has been devoted to characterizing the precise time course of these processes, that is, their respective order and duration. As is evident from previous reviews (Indefrey and Levelt, 2004; Indefrey, 2011) this issue is particularly complex and our current knowledge, which relies on the comparison of disparate sources of evidence, is still incomplete.

Information about when and how the different encoding processes unfold can be extracted from different sources (see Indefrey and Levelt, 2004 for a comprehensive review). A first way to obtain such information is to design paradigms that target specific processes. However, these approaches do not allow estimating directly the time course of specific processes. For instance, Jescheniak and Levelt (1994) had participants perform a picture word matching task and subtracted an approximation of the time devoted to response preparation and execution from the overall response times to conclude that it takes less than $150 \mathrm{~ms}$ to access lexical concepts. Another approach to gain insight into the time course of word production processes is the use of priming or interference paradigms where the prime (an auditory or visually presented word distractor) occurs at different time points relative to picture presentation (or SOA, for stimulus onset asynchrony e.g., Glaser and Düngelhoff, 1984). Distractors typically have a phonological, semantic or sometimes syntactic relationship with the target word. Depending on the SOA at which a given distractor type affects responses, conclusions have been drawn on the temporal relationship between specific encoding processes (e.g., Schriefers et al., 1990), while not necessarily on their precise time course.

A third important source of information on the time course of cognitive processes comes from EEG or MEG studies with ERPs, which allow one to track temporal information with a precision at the millisecond range. Different paradigms have been used so far, including delayed picture naming tasks (Jescheniak et al., 2003; Cornelissen et al., 2004; Vihla et al., 2006; Laganaro et al., 2009), implicit naming or metalinguistic tasks (e.g., Thorpe et al., 1996; Van Turennout et al., 1998; Schmitt et al., 2000; Jescheniak et al., 2002; Rodriguez-Fornells et al., 2002; Zhang and Damian, 2009) and, more recently, overt picture naming (see Ganushchak et al., 2011; Strijkers and Costa, 2011 for a critical review of EEG/MEG speech production studies). ERP paradigms using overt picture naming paradigms are the most relevant as they truly involve an overt production of the target words. Studies conducted so far with this task have addressed one single step or sub-step of the production process each. They have usually involved a manipulation of the experimental conditions (e.g., semantic context, Costa et al., 2009; Aristei et al., 2011; Blackford et al., 2012) or of the materials, using factorial or semi-factorial designs, i.e., with two subsets of items varying in terms of a specific predictor being compared (e.g., name agreement, Cheng et al., 2010; age of acquisition, Laganaro and Perret, 2011; lexical frequency, Levelt et al., 1998; Strijkers et al., 2010).

In the present study, we extend this second approach, by considering most variables described in previous chronometric and ERP studies at once.

A similar methodological approach involving multiple regression analyses between ERPs and psycholinguistic factors was first introduced by Hauk et al. (2006) in a visual word recognition paradigm. In their study the authors orthogonalized four theoretically relevant psycholinguistic factors in visual word recognition and investigated their effects on ERP regression coefficients, with the aim of determining which factors affected neurophysiological activity, and to obtain information on the precise time course of their effects during word processing. Dien et al. (2003) also introduced a novel ERP approach aimed at avoiding the grouping of experimental stimuli in few categories and the potential subsequent loss of information. This was achieved by averaging the items across participants, rather than across trials, in order to investigate correlations between stimulus characteristics and the neurophysiological activity.

In relation to these previous studies, here the analyses of the effects of psycholinguistic variables on neurophysiological activity are carried out on the duration of periods of stable global electrophysiological activity on the whole word encoding process from picture onset to articulation. This allows to determine the origin of the cost generated by these variables on vocal response times and to assess the effect exerted by psycholinguistic factors on the different stages of information processing. 
With respect to Dien et al. (2003), the item-averaging approach was further improved insofar as here ERP trials were not averaged and template maps issued from the spatio-temporal segmentation of group-averaged ERPs were backfitted in single trials. Single trial approaches have proved reliable and effective as they allow preserving the complete variability of the EEG dataset, which is usually lost when averaged responses are utilized (e.g., De Lucia et al., 2007, 2010). Thus, our approach also extends the classical topographic analysis in fitting the spatio-temporal segmentation of the group-averaged ERPs back into the single trials rather than into the subject-averaged ERPs.

This analysis is likely to inform us on two different issues. Firstly, ERP modulations by variables that can be unambiguously attributed to given word encoding processes will provide precise information on the time course of these specific processes. Secondly, if effects are found for variables whose attribution still lacks empirical support, our findings, together with existing estimates of the time course of the production process, will allow us to propose a specific locus for these variables.

Based on the existing literature, the following variables were included in our analysis: Visual complexity, Concept familiarity, Image agreement, Name agreement, Lexical frequency, Age of acquisition, Word length, Phonological neighborhood, and Phonotactic probability. Figure 1 shows these variables and the processing level with which they have been associated in previous studies. Further details on each variable are provided below.

Visual complexity, defined as "the amount of detail or intricacy of line in a picture" (Snodgrass and Vanderwart, 1980), has been associated with object recognition. Empirical evidence in favor of this insofar intuitive hypothesis has recently been found by Martinovic et al. (2008). The authors reported that the visual complexity of line drawings modulated waveforms in the $\mathrm{P} 1$ range, a time window likely associated with visual processes and object recognition. Note also that whereas a few studies found increasing response latencies for more complex pictures (Attneave, 1957; Alario et al., 2004), other studies failed to find differences in response latencies between high and low complexity pictures (Paivio et al., 1989; Snodgrass and Yuditsky, 1996; Barry et al., 1997; Cuetos et al., 1999; Bonin et al., 2002, 2003; Janssen et al., 2011) or reported the opposite effect, i.e., decreased production latencies for more complex pictures (Szekely et al., 2005).

Concept familiarity is defined as "the degree to which participants come in contact with or think about the concept" (Snodgrass and Vanderwart, 1980, p. 183). It has been estimated by asking participants to rate on a five-point scale (from 1. very unfamiliar to 5. very familiar object), the extent to which the concept associated with a picture was recurrent in their thoughts or frequently encountered (Alario and Ferrand, 1999). Concept familiarity has been hypothesized to affect the links between picture representations and their semantic representations (Hirsh and Funnell, 1995). To our knowledge, however, this hypothesis has not been confirmed empirically. As for the previous variable, effects of concept familiarity on picture naming latencies have not been reported systematically. A few studies found increasing response latencies for less familiar pictures (Snodgrass and Yuditsky, 1996; Ellis and Morrison, 1998), while other studies failed to find

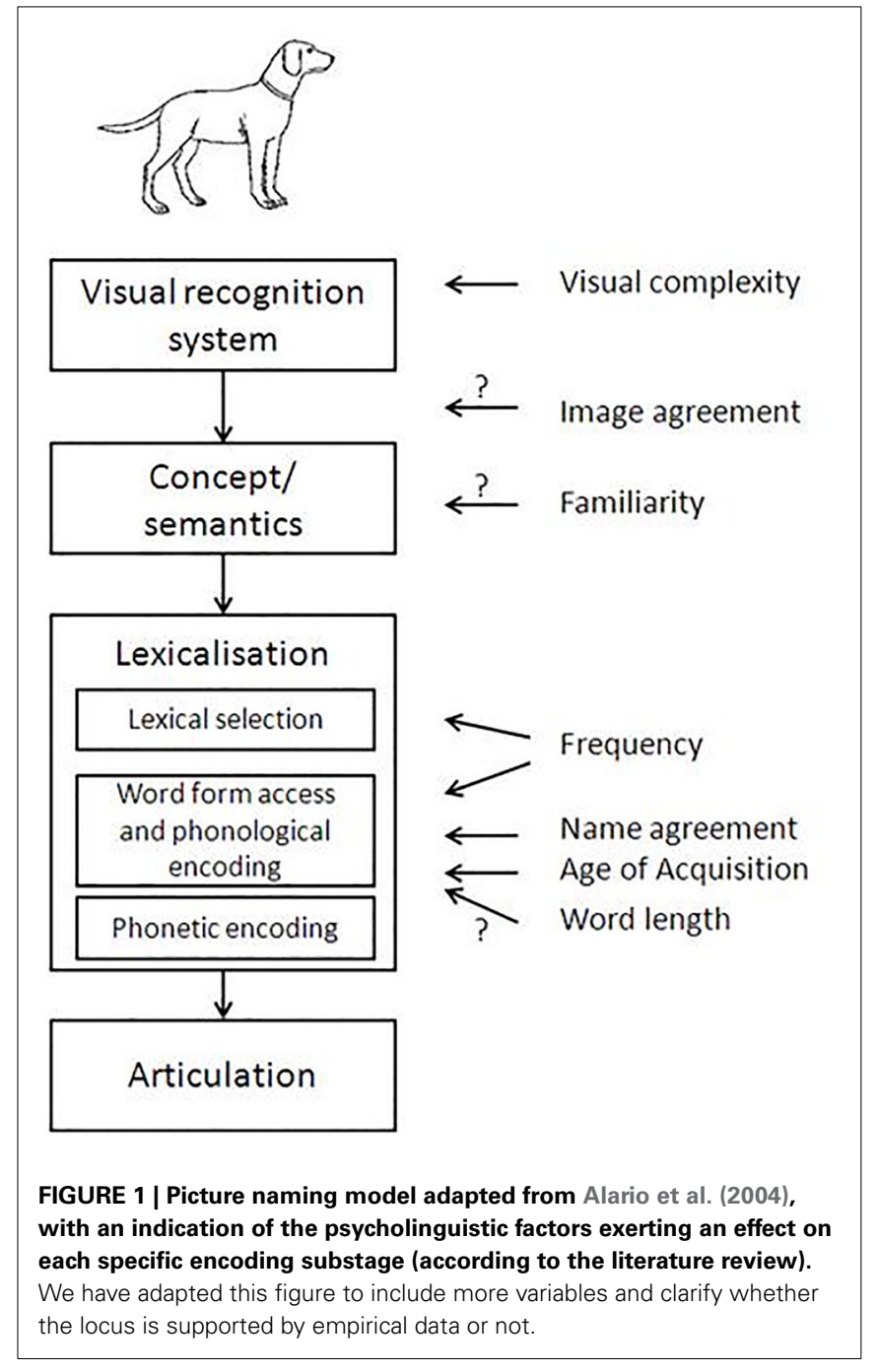

differences in response latencies between items of high and low familiarity (Barry et al., 1997; Dell'Acqua et al., 2000; Bonin et al., 2002, 2003; Alario et al., 2004).

Lexical frequency refers to how often the word is used in a language. Shorter response latencies for more frequent words have been reported many times in the psycholinguistic literature (e.g., Jescheniak and Levelt, 1994; Barry et al., 1997; Ellis and Morrison, 1998; Griffin and Bock, 1998; Alario et al., 2004). However the effect of lexical frequency is mostly found in factorial designs and often disappears when Age of Acquisition is controlled for or entered in a regression model (Carroll and White, 1973; Morrison et al., 1992; Barry et al., 1997, 2001; Bonin et al., 2002, but see Snodgrass and Yuditsky, 1996; Barry et al., 1997; Ellis and Morrison, 1998). Some authors attribute the effect of lexical frequency to lexical (lemma) selection (Dell, 1990; Alario et al., 2002; Navarrete et al., 2006) while others attribute it to phonological encoding (Jescheniak and Levelt, 1994; Levelt et al., 1999). Recent research suggests an effect of lexical frequency at both processing stages (Kittredge et al., 2008; Knobel et al., 2008). An ERP study by Strijkers et al. (2010) reported waveform divergences between high and low frequency words at $180 \mathrm{~ms}$ after picture 
presentation. The authors suggested that this time period corresponds to the initiation of lexical selection. Further evidence in favor of a lexical-phonological locus of the word frequency effect is provided by fMRI overt picture naming studies. Graves et al. (2007) reported a correlation between lower word frequency and activity in the left posterior superior temporal gyrus, a region previously associated with lexical-phonological processing in word production (see Price, 2012 for a review). Wilson et al. (2009) showed activation related to word frequency effect in an anatomical contiguous region (the left posterior inferior temporal gyrus).

Image agreement refers to the proximity between a represented object and its mental image. Participants were asked to rate on a five-point scale (from low agreement to high agreement) the agreement between a pictorial stimulus and their own mental representation of the depicted object (Alario and Ferrand, 1999). Effects of image agreement on naming latencies have been found in several studies (Barry et al., 1997, see also Alario et al., 2004). Snodgrass and Vanderwart (1980) hypothesized that this measure would affect image recognition. To our knowledge, no empirical arguments have yet come to back up this view.

Name agreement is a measure of the degree of association between the picture and the corresponding modal name. It is estimated by examining the number of different names participants provide for a given picture. It has been shown that when participants give many different names for a same picture (low name agreement), production latencies are longer (Lachman et al., 1974; Paivio et al., 1989; Vitkovitch and Tyrrell, 1995; Snodgrass and Yuditsky, 1996; Barry et al., 1997; Alario et al., 2004; Kan and Thompson-Schill, 2004). Name agreement does not affect object decision reaction times, suggesting that the effect of this variable on naming responses occurs during lexical retrieval, and/or during phonological encoding (Johnson et al., 1996; Alario et al., 2004). In line with this hypothesis, Cheng et al. (2010) reported an effect of Name Agreement on ERPs in a silent picture naming task at $290 \mathrm{~ms}$ from picture onset, a time window usually associated with phonological encoding processes. Note that these authors also found an early influence of Name agreement in the P1 time window (around $120 \mathrm{~ms}$ after picture onset). According to the authors, this early influence could reflect the enhanced recruitment of visual attentional resources for pictures with low relative to high name agreement.

Age of acquisition (AoA) refers to the age at which a given word is learnt. Numerous studies have shown that words acquired earlier are named faster, and that different brain activations underlie the processing of early and late acquired words (see for instance Hernandez and Fiebach, 2006; for brain correlates of AoA effects in word reading). The effect appears to be similar with subjective estimates of AoA (e.g., Morrison and Ellis, 1995; Chalard and Bonin, 2006) and with objective measures taken from corpora of child speech (Morrison et al., 1997; Ellis and Morrison, 1998). Reliable effects have also been found when frequency is controlled for (Barry et al., 2001). Some authors have ascribed AoA effects to lexical-semantic encoding stages, reporting independent AoA effects in tasks which did not necessarily involve access to the word form, but rather lexical-semantic processing, such as semantic blocking in picture naming and semantic categorization
(Belke et al., 2005; Johnston and Barry, 2005). Other studies converge toward a lexical-phonological locus of AoA. Morrison et al. (1992) found that AoA was a significant predictor of picture naming speed but did not affect semantic categorization, suggesting that the effect originates in the retrieval and articulation of object names. Morrison and Ellis (1995) reported AoA effects in lexical decision and in immediate but not delayed picture naming, concluding for its implication in retrieval of the word form. Recent ERP data (Laganaro and Perret, 2011; Laganaro et al., 2012) revealed that AoA modulated ERPs recorded during picture naming in a relatively late time window compatible with retrieval of the word form.

\section{WORD LENGTH}

Studies on the influence of word length on picture naming latencies have reported mixed outcomes (see Cuetos et al., 1999; Santiago et al., 2000; Roelofs, 2002 for shorter latencies for shorter words and Snodgrass and Yuditsky, 1996; Bachoud-Lévi et al., 1998; Dell'Acqua et al., 2000; Damian et al., 2010 for null effects). As for the attribution of this effect, most models of word production assume that longer words should take longer to be named due to the sequential insertion of phonemes in the metrical structure during phonological encoding. Hence, if length does have an effect, we can assume it is located after lexical retrieval, most likely in late time windows associated with phonological encoding. Graves et al. (2007) reported word length effects in primary motor regions, suggesting for the involvement of such factor during phonetic encoding and implementation of the articulatory routine.

More recently, other variables such as phonological neighborhood density (Vitevitch, 2002; Vitevitch and Sommers, 2003) and phonotactic probability (Vitevitch et al., 2004) have been shown to affect speech production. The precise locus of the effect of these variables is still controversial. However, as they were not considered or balanced across conditions in previous studies, they may have influenced the outcome through their correlation with other predictors.

Building on previous chronometric and ERP studies, the present research aims at determining the time course of picture naming latencies predictors, this time course being instantiated in specific and experimentally defined periods of electrical stability (topographic maps or event-related brain potential microstates). Topographic analysis is a reference-independent measure of electrical potential variations in the brain. The main theoretical assumption of this approach is that different topographic maps are generated by different cerebral sources and supposedly different cognitive processes (Michel et al., 2009). These analyses do not only provide an insight into when processes differ but also into "how they differ in terms of likely underlying neurophysiologic mechanisms" (Murray et al., 2008, p. 249). Another characteristic of topographic analysis is that it is not affected by the choice of a reference electrode (see Michel et al., 2009).

The topographic analysis entails a spatio-temporal segmentation of the ERPs in periods of electrophysiological stability (topographic maps); crucially for the purposes of this study, topographic analysis provides information regarding the precise time course of each stable electric field configuration, with no need 
for a priori focus on specific time windows. The application of this analysis to stimulus- and response-aligned ERPs adapted to each individual production latency (following Laganaro and Perret, 2011), allows us to cover the entire encoding process from picture onset to articulation and to capture those encoding processes that are truncated when fixed stimulus-aligned ERP time-windows are analyzed. The standard procedure in topographic analysis requires a time point by time point computation of the spatial correlation between the template maps observed in the group-average ERP in $n$ different experimental conditions and individual ERP data. This methodology allows one to investigate for instance the association between template maps and particular experimental conditions (e.g., Murray et al., 2008) or to look for differences in the duration of periods of stable electrophysiological stability across experimental conditions (e.g., Laganaro et al., 2012). This in turn allows one to draw conclusions about the dynamics of the cognitive processes involved in these different conditions. In the present study, we will conduct mixed-effects regression analyses to determine the influence of multiple variables on picture naming latencies and ERPs. Differently from the traditional approach in topographic analysis, here the time point by time point comparison of the template topographic maps identified in the grand-average ERPs will be conducted on a trial by trial basis rather than in subject-averaged ERPs. This will allow a thorough verification at the level of single trial activitycorresponding to different linguistic stimuli-of the template maps issued from the spatio-temporal segmentation of the groupaveraged ERP and the analysis of the effects of a set of linguistic properties related to the words, i.e., to the trials.

This approach has several advantages. Firstly, given that many variables can be considered at once, it provides information on the time course of the whole production process rather than on a single processing step. This is important, as estimates of the time course of word production can be more precise if extracted from a single experiment rather than from different studies. Secondly, the inclusion of many variables also ensures that a given variable is significant over and above the effect of other variables. Thirdly, this methodological approach enables the use of continuous variables rather than categorical ones. As underlined by several researchers (e.g., Balling, 2008; Baayen, 2010), factorial designs have many disadvantages when compared to regression designs, including loss of power and influence of confounding variables.

An example of the application of the trial by trial approach presented here can be found in Bürki and Laganaro (2014), where it has been applied as a statistical validation tool for the comparison of an experimental condition involving multi-word production in comparison to bare noun production in a picture naming task.

\section{METHODS \\ PARTICIPANTS}

Thirty one undergraduate students (7 men), recruited at the University of Geneva participated in the study. They were all native French speakers, aged between 18 and 36 (mean $=24$ ). They were all right-handed as determined by the Edinburgh Handedness Scale (Oldfield, 1971). Twenty-one participants performed the picture naming task in the framework of the present study and 10 subjects were selected among the participants with the highest rate of uncontaminated EEG epochs from a previous study using the same material and procedure (Laganaro et al., 2012).

The participants gave their informed consent-approved by the local ethics committee-and were paid for their participation.

\section{MATERIAL}

The stimuli were 120 words and their corresponding black and white line drawings from two French databases (Alario and Ferrand, 1999; Bonin et al., 2003), from which a subset of 100 items was selected. The retained 100 words were those with the highest rate of correct responses (global accuracy: $95.2 \%$ ) and with a minimum of 20 uncontaminated EEG epochs (see pre-analyses). The stimuli characteristics are provided in Supplementary Material.

\section{PROCEDURE}

Participants were tested individually in a soundproof dark room. They sat $60 \mathrm{~cm}$ in front of the computer screen. Pictures were presented in constant size of $9.5 \times 9.5 \mathrm{~cm}$ (approximately $4.52^{\circ}$ of visual angle) on a gray screen. Before the experiment, participants were familiarized with all the pictures and their corresponding names on a paper sheet. An experimental trial had the following structure: a fixation sign was presented for $500 \mathrm{~ms}$ followed by the presentation of a picture on the screen for $2000 \mathrm{~ms}$. Participants were asked to name the picture as quickly as possible. A $2000 \mathrm{~ms}$ blank screen was displayed before the next trial. Items were presented in different pseudo-random orders for each participant, which were controlled to avoid for semantically or phonologically related items to appear in direct succession. The experiment lasted about $15 \mathrm{~min}$ and started with four warming-up filler trials.

\section{BEHAVIORAL ANALYSES}

Each spoken response was first checked for accuracy. Noresponses, wrong responses (i.e., the participant produced a different name than the one expected), hesitations and/or autocorrections during articulation were counted as errors. A total of 50 responses ( $1.6 \%$ of the total) were excluded.

Response times (defined as the time between the onset of picture presentation and the onset of the verbal response) were precisely defined on the basis of the spoken responses' spectrogram. We further excluded the 62 responses ( $2 \%$ of the total) with a response time below $500 \mathrm{~ms}$ or above $1500 \mathrm{~ms}$.

\section{EEG RECORDING AND PRE-ANALYSIS}

A high density EEG (128 channels covering the scalp) was recorded, using the Active-Two Biosemi system (Biosemi V.O.F. Amsterdam, Netherlands). Signals were sampled at $512 \mathrm{~Hz}$ and the band-pass filters were set between 0.16 and $100 \mathrm{~Hz}$. Postacquisition analyses were conducted with the Cartool Software (Brunet et al., 2011). Stimulus-aligned epochs-from picture onset to $450 \mathrm{~ms}$ - and response-aligned epochs - covering from -550 to $100 \mathrm{~ms}$ before the onset of each single verbal response- were extracted and band-pass filtered between 0.2 and $30 \mathrm{~Hz}$. All epochs with out-of-range amplitudes $( \pm 100 \mu \mathrm{V})$ were excluded. The remaining epochs were visually checked for 
undetected artifacts caused by eye blinking or muscular activity. Contaminated epochs were excluded from the averaging process. Bad channels were interpolated on each epoch following a 3D spline interpolation method. Only epochs for which both stimulus-aligned and response-aligned ERPs were available were retained. Stimulus and response-aligned ERPs were merged together on the basis of each trial's reaction times and the overlapping ERP from the response-aligned signal was removed. This procedure is designed to obtain an ERP covering the whole time window of encoding, from picture onset to $100 \mathrm{~ms}$ before the initiation of articulation (see Laganaro and Perret, 2011; Laganaro et al., 2012 for further applications). It was applied to epochs averaged across subjects $(N=31)$ and to single epochs (single trials, $N=2693)$.

\section{ERP ANALYSIS}

A topographic pattern analysis was carried out. Topographic analysis allows compressing variability of ERPs with a procedure called "spatio-temporal segmentation" in a series of template maps, which summarize and explain at best the data (usually the grand-average). This spatio-temporal segmentation was applied to the subject-averaged data using a Topographic Atomize \& Agglomerate Hierarchical Clustering (Pascual-Marqui et al., 1995; Murray et al., 2008). In order to exclude short periods of topographic instability, a given stable ERP topography had to be present for at least $20 \mathrm{~ms}$ to be retained. A combination of crossvalidation and Krzanovski-Lai criteria was adopted to select the optimal number of template maps. The Krzanovski-Lai criterion is based on the analysis of the curvature of the dispersion curve (W), which represents a quality measure of the segmentation. The KL value, representing a relative measure of such curvature, usually reaches the peak in correspondence with the optimal clustering (Murray et al., 2008). We then compared the template maps obtained in the segmentation of the group-averaged ERPs with each individual ERP and with the single trial evoked potentials, this procedure is called "fitting." In the fitting procedure, each time point of each individual ERP is labeled on the basis of the spatial correlation it bears with one of the template maps issued from the segmentation of the grand-average. A set of fitting time-windows is determined, based on the results of the groupaveraged segmentation; the template maps included in such time windows are then fitted back in the same time window of each subject and single trial ERP. The procedure is therefore temporally constrained and requires at least two template maps to be included in a particular time window. This procedure provides information on the presence of each stable topographic configuration time point per time point and therefore also on their duration. Statistical analyses are then carried out on these two measures.

\section{STATISTICAL ANALYSES AND SELECTION OF INDEPENDENT VARIABLES}

Behavioral and EEG responses were analyzed by means of mixedeffects regression models (e.g., Goldstein, 1987, 1995; Baayen et al., 2008). All statistical analyses were conducted with the statistical software R (R Development Core Team, 2007) and mixed-effects models were computed with the packages lmerTest
(Kuznetsova et al., 2013) and lme4 (Bates and Sarkar, 2007). Statistical analyses on behavioral responses aimed at determining the predictors of picture naming latencies (i.e., time between onset of picture and onset of articulation) in our dataset. Statistical analyses on ERPs aimed at determining the predictors of the duration of the stable topographic maps defined by the spatio-temporal analysis described above. Mixed effects regression models were thus run separately for each topographic map, with the duration of the map as the dependent variable.

In each regression model, participants and items were entered as crossed random effects. The same set of variables was entered as fixed effects, always in the same order: the Levensthein phonological distance measure [i.e., mean Levensthein distance (LD) from the stimulus to its 20 closest neighbors, the LD between two words being defined as the minimum number of insertions, deletions or substitutions required to generate one word from the other, see Yarkoni et al., 2008] as a measure of phonological neighborhood density. Positional segment frequency and Positional diphone frequency (i.e., sum of $\log$ frequencies of all words that contain a given segment or diphone in a given position, divided by the log frequency of all words with a segment/diphone in this position) as measures of phonotactic probability (Vitevitch and Luce, 2004); the logarithm of lexical frequency (LexF), as given for Movies and Books in the French "Lexique" database (New et al., 2004, 2007); concept familiarity (CFam); the visual complexity of the pictures (VCom), Image agreement (IAgr), Name agreement (NAgr, i.e., the percentage of participants who produced the modal name, and the $\mathrm{H}$ measure, see Snodgrass and Vanderwart, 1980 for details), and Age of acquisition (AoA). Measures accounting for the five last variables were taken from either Bonin et al. (2003) or Alario and Ferrand (1999) databases (these two databases provide similar measures for different sets of pictures).

For each dependent variable, we also conducted a second model in which we introduced in addition the number of syllables as a fixed effect and removed the Levenshtein phonological distance measure and phonotactic probability. This was done because number of syllables and the other two measures were correlated above 0.6 . Given that these latter models were always highly similar to the first and that number of syllables never reached significance, we only report the statistical values of the models with the Levenshtein phonological measure distance and phonotactic probability, without the number of syllables.

When a given predictor could be represented by more than one measure, we examined the influence of each of these measures in separate models. For instance, lexical frequency can be measured by counting the number of occurrence of a given word in a collection of books (written lexical frequency), or in movies subtitles (spoken lexical frequency). In French, the two measures are available. We thus conducted two statistical models, one with written frequency and another with spoken frequency. This was done to ensure that the absence of an effect for a given variable was not due to the selection of the wrong measure and favor the use of measures that best accounted for our dataset.

Items and participants were entered in the model as random effects. Unless otherwise stated, all the effects we report as significant stem from models with a random slope allowing for these effects to differ among participants. Following Baayen (2008) 
each model was fitted twice, the second time without the residuals of the regression model larger than 2.5 times the standard deviation. Results with and without the residual outliers did not differ and the results we report stem from models without these outliers. Alpha was set to 0.05 in the response time analysis; in the ERP analyses, where five different analyses were conducted, a Bonferroni correction was applied to adjust for multiple testing (alpha set to 0.01). For each analysis, we further report the marginal (associated with the fixed effects) and conditional (associated with the fixed plus the random effects of the model) $\mathrm{R}$ squares (Nakagawa and Schielzeth, 2013). We also checked that there was no potentially harmful multicollinearity in our models (redundancy tests). This was never the case; all models had tolerance values above 0.5 .

\section{RESULTS \\ BEHAVIORAL RESULTS (PRODUCTION LATENCIES)}

The dataset considered in the analyses contained the 2693 data points for which participants had produced a correct response and whose epoch was included in the ERP analysis. The mean production latency was $805 \mathrm{~ms}(S D=181 \mathrm{~ms})$.

Results revealed main effects of age of acquisition, name agreement, and image agreement. Production latencies increased with age of acquisition $(\beta=40.61, t=3.36, p<0.01)$ and decreased with higher name agreement $(\beta=-3.38, t=-4.87$, $p<0.0001)$ and image agreement $(\beta=-22.24, t=-3.17, p<$ $0.01)$ values. None of the other predictors was significant. Statistical values for all predictors are presented in Table 1. The marginal and conditional $\mathrm{R}$ squares for this model were respectively of 7 and $52 \%$. Note that the statistical model did not converge until we removed the random slope allowing for the effect of name agreement to vary amongst participants.

\section{ERPs}

The spatio-temporal segmentation of the grand average from $50 \mathrm{~ms}$ after picture onset to $100 \mathrm{~ms}$ before articulation onset yielded 5 different topographic patterns, which accounted for $95.88 \%$ of the overall variance in the data (see Figure 2 ). Three time windows were chosen for the fitting procedure, based on the result of the segmentation on the group-average and in order to include at least two map templates in each period: from 50 to $180 \mathrm{~ms}$, from 180 to $460 \mathrm{~ms}$ and from 460 to $100 \mathrm{~ms}$ before articulation. The fitting time-windows were set within rather than at

Table 1 | Summary of the mixed effects regression model for the response latencies.

\begin{tabular}{lccl}
\hline & $\boldsymbol{\beta}$ & $\boldsymbol{t}$ & $\boldsymbol{p}$ \\
\hline Phonological Levenshtein distance & -24.24 & -1.74 & $>0.08$ \\
Positional segment frequency & 12.42 & 0.056 & $>0.9$ \\
Lexical frequency & -2.25 & -0.70 & $>0.4$ \\
Familiarity & -1.19 & 0.32 & $>0.7$ \\
Visual complexity & -6.14 & -0.72 & $>0.4$ \\
Image agreement & -22.24 & -3.17 & $<0.01$ \\
Name agreement & -3.38 & -4.87 & $<0.0001$ \\
Age of acquisition & 40.61 & 3.36 & $<0.01$
\end{tabular}

the end of the time-periods of stable electrophysiological activity (topographic maps) to account for between subject and trial variability: map templates crossing the fitting borders were entered in the two consecutive fitting periods (maps " $\mathrm{A}$ " and " $\mathrm{B}$ " in the first fitting period, "B," "C," and " $\mathrm{D}$ " in the second period, "D" and " $E$ " in last period). In order to ensure that the five topographic maps were not driven by random noise in the trial by trial data, we first performed a topographic consistency test (TCT, Koenig and Melie-García, 2010) on the trial ERPs from a subset of randomly selected items. This analysis revealed that periods of consistent topographic patterns across single trials extended from $\sim 70 \mathrm{~ms}$ to the end of the analyzed period ( $100 \mathrm{~ms}$ before articulation), with the exception of a short period of topographic inconsistency from $\sim 150$ to $\sim 180 \mathrm{~ms}$ in all examined items (see Supplementary Material).

A computation of Map presence was then performed separately in ERP trials and subjects. Information on map presence is obtained during the fitting procedure. Each time point of each individual trial or subject-averaged ERP is labeled accordingly to the template map with which it shares the highest spatial correlation. A measure of map presence can therefore be obtained by calculating the ratio between the number of trials in which the map was found and the total number of trials (or sample).

Results are summarized in Figure 2. To ensure that the topographic template maps issued from the spatio-temporal segmentation of the group-averaged ERP were sufficiently representative of the single trials ERPs, the Global Explained Variance (GEV) of each template map was calculated in subjects and single trials. The GEV is a measure informing on how extensively a given template map describes the variance of the considered dataset (e.g., Murray et al., 2008). Results of presence and GEV for each map in the fitting in both subjects and trials are summarized in Figure 2. The percentage of map presence is similar or higher in the single trials than in the subjects. The GEV is about $20 \%$ lower in the single trials with respect to subjects for maps A, C, and D, but it is higher in the single trials than in the subjects for the last period of topographic stability (map E).

Crucially for the single trial analysis carried out here, all maps appeared in at least $89 \%$ of the trials. The three variables found to affect production latencies were entered as fixed predictors in each regression analysis along with the other psycholinguistic variables as covariates. This ensured that the effects of some were not byproducts of their correlations with other variables.

Results of the mixed effects regression model for each stable electrophysiological pattern are summarized in Table 2.

The duration of the second map (map " $\mathrm{B}$ "), which lasted from about 140 to $180 \mathrm{~ms}$ after picture onset, decreased with visual complexity $(p<0.01)$. Map D, which started around $380 \mathrm{~ms}$ after picture onset and lasted for about $240 \mathrm{~ms}$, decreased with higher Image Agreement $(p<0.01)$ and Name agreement $(p<0.0001)$ values. There was also a marginally significant effect of the word Age of Acquisition ( $p=0.015$ ). The last stable pattern (map "E" in Figure 2), which started about $620 \mathrm{~ms}$ after picture onset and lasted until at least $100 \mathrm{~ms}$ before the onset of articulation had a longer duration for late-acquired words $(p<0.01)$ and words with low name agreement values $(p<0.0001)$. The complete statistical models are reported in Supplementary Material. Note that 

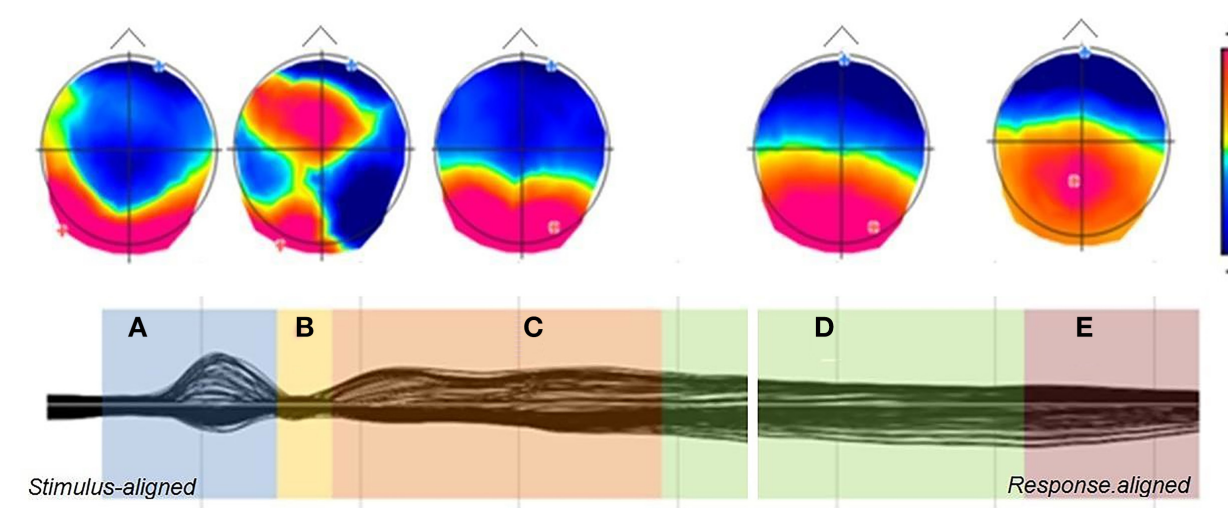

$100 \mathrm{~ms}$

$500 \mathrm{~ms}$

$600 \mathrm{~ms}$

\begin{tabular}{lcccccccccc}
\hline & \multicolumn{2}{c}{ MapA } & \multicolumn{2}{c}{ MapB } & \multicolumn{2}{c}{ MapC } & \multicolumn{2}{c}{ MapD } & \multicolumn{2}{c}{ MapE } \\
& Presence & GEV & Presence & GEV & Presence & GEV & Presence & GEV & Presence & GEV \\
\cline { 2 - 10 } Trials (N= 2693) & $92 \%$ & $23 \%$ & $89 \%$ & $1.5 \%$ & $92 \%$ & $16 \%$ & $98 \%$ & $25 \%$ & $99 \%$ & $19 \%$ \\
Subjects (N=31) & $90 \%$ & $52 \%$ & $35 \%$ & $1.5 \%$ & $94 \%$ & $39 \%$ & $94 \%$ & $38 \%$ & $90 \%$ & $14 \%$ \\
\hline
\end{tabular}

FIGURE 2 | Top: Grand-average ERPs (128 electrodes) from onset to $100 \mathrm{~ms}$ before articulation and temporal distribution of the topographic maps revealed by the spatio-temporal segmentation, with map templates for the six stable topographies (positive values in red and negative values in blue with display of maximal and minimal scalp field potentials). Bottom: Presence and GEV of each map template in the fitting in the single trials and subject ERPs.

Table 2 | Summary of the mixed-effects regression model for the duration of periods of stable electrophysiological activity (topographic maps).

\begin{tabular}{|c|c|c|c|c|c|}
\hline & $\begin{array}{c}\text { Map A: } \\
\sim 50-140 \mathrm{~ms} \beta, t \text {, sign }\end{array}$ & $\begin{array}{c}\text { Map B: } \\
\sim 140-180 \mathrm{~ms} \beta \text {, } t \text {, sign }\end{array}$ & $\begin{array}{c}\text { Map C: } \\
\sim \mathbf{1 8 0 - 3 8 0 ~} \mathrm{ms} \beta \text {, } t \text {, sign }\end{array}$ & $\begin{array}{c}\text { Map D: } \\
\sim 380-620 \mathrm{~ms} \beta, \mathrm{t}, \text { sign }\end{array}$ & $\begin{array}{c}\text { Map E: } \\
\sim 620 \text {-articulation } \beta, t \text {, sign }\end{array}$ \\
\hline VCom & & $-1.92, t=-2.85, * *$ & & & \\
\hline IAgr & & & & $-8.67, t=-2.75, * *$ & \\
\hline NAgr & & & & $-1.08, t=-4.17, * * *$ & $-0.67, t=-4.73, * * *$ \\
\hline
\end{tabular}

${ }^{* *} p<0.01 ;{ }^{* * *} p<0.001$.

VCom, visual complexity; CFam, Concept Familiarity; IAgr, Image Agreement; NAgr, Name Agreement; AoA, Age of Acquisition.

the model for map D did not converge with a random slope for Name Agreement, and the one for map E did not converge until the removal of the random slopes allowing for the effects of Name Agreement and Image agreement to differ among participants.

\section{DISCUSSION}

The aim of the present work was to gain insight into the dynamics of word production in picture naming tasks. To this end, we analyzed the effects of a set of theoretically relevant variables on response times as well as on an electrophysiological measure, namely the duration of periods of stable EEG activity (topographic maps). A multiple regression approach was implemented on trial by trial ERPs covering the entire encoding period from picture onset to $100 \mathrm{~ms}$ before articulation. This approach allowed us to select the variables that truly influenced response times in our dataset and to pinpoint the exact time windows at which these variables exerted their influence.

Three out of the larger set of examined variables had robust independent effects on production latencies: word age of acquisition, name agreement, and image agreement. Overall, these results confirm previous published data on the predictors of picture naming latencies. Effects of name agreement, age of acquisition, and image agreement have indeed been reported in many studies (see Alario et al., 2004 for reviews). The five remaining variables (lexical frequency, visual complexity, familiarity, word length, phonological neighborhood, and phonotactic probability) have also been reported to affect production latencies in previous studies but much less systematically, especially when multiple regression designs were used (see Alario et al., 2004). Crucially for our purposes, the three variables that had an effect on RTs also significantly affected the duration of periods of topographic stability. The results are summarized in Figure 3. In what follows, we will discuss these results in the light of previous psycholinguistic and ERP findings.

The visual complexity of the pictures modulated ERPs but did not affect RTs. Visual complexity modulated the duration of the second period of topographic stability (topographic map B, from $\sim 140$ to $\sim 180 \mathrm{~ms}$ ). The shorter duration for more complex 


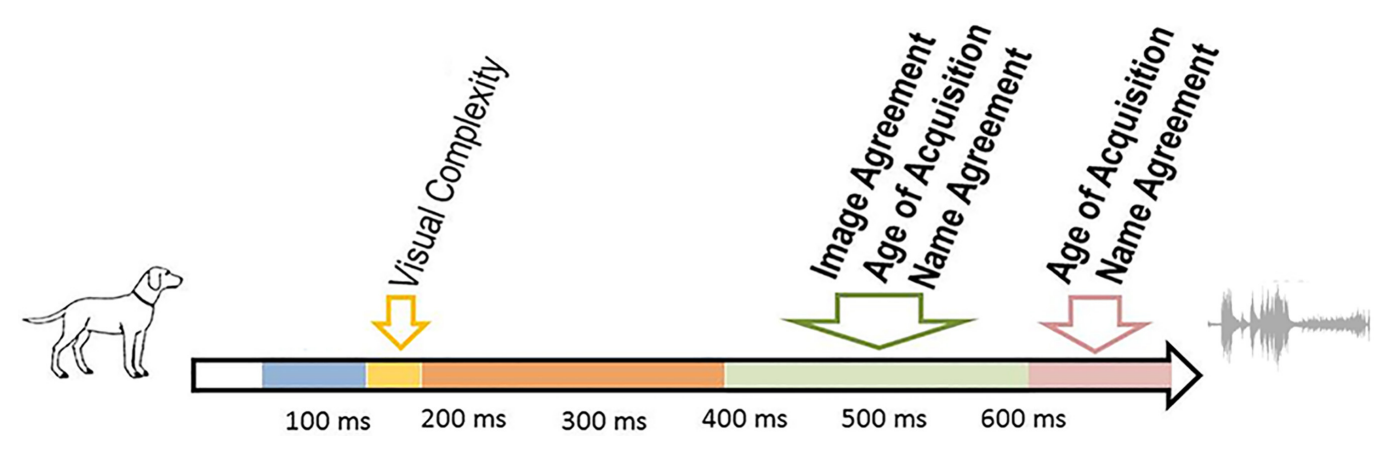

FIGURE 3 | Summary of the time course of the significant predictors in the ERP analyses. Variables that also affected RTs are in bold.

pictures likely reflects the fact that pictures can be recognized faster when they contain more details; this is in agreement with studies reporting shorter production latencies for more complex pictures (Szekely et al., 2005, but see Alario et al., 2004). The effect falls within the P1-N1 range, traditionally associated with visual-conceptual processing (Schendan and Kutas, 2003). Similar results have been reported by Martinovic et al. (2008, Experiment 2) who compared ERPs of pictures with high vs. low visual complexity in a gender decision task. Visual complexity did not affect response times, but modulated ERPs in the P1 range with higher amplitudes and increased evoked gamma-band activity, but also earlier peak latency for high complexity relative to low complexity pictures. The upper boundary of the visual complexity effect likely indicates that the limit of pre-linguistic processing in picture naming lays at approximately $180 \mathrm{~ms}$. This result further supports the reliability of the trial by trial approach adopted here. An influence of the predictor Visual Complexity on the duration of the stable topographic configuration in the first $180 \mathrm{~ms}$ is perfectly consistent with the robust and extensive evidence associating this specific time-window with the processing of visual object information.

Name agreement (NAgr) modulated the duration of two stable electrophysiological patterns in the time window extending between approximately 380 after picture onset and $100 \mathrm{~ms}$ before articulation (Maps "D" and "E" in Figure 2). The duration of these two maps decreased with higher name agreement values. Name agreement is an objective measure of the degree of association between the picture and its modal name.

Low agreement values can have two alternative sources: either the picture is visually ambiguous, or it has several possible names. The finding that the effect of Name agreement occurs rather late in the production process suggests that in the present study, the effect results from the latter and likely takes place during the word's phonological encoding. The erroneous responses provided by the participants in Alario and Ferrand (1999) and Bonin et al. (2003) to the stimuli with low NA support this hypothesis, as the majority of errors were synonyms of the modal name. This finding is in line with previous attributions of this effect to lexical retrieval and/or phonological encoding (Johnson et al., 1996; Alario et al., 2004, see the Introduction) as well as with Cheng et al. (2010) who reported an influence of Name agreement around $290 \mathrm{~ms}$ after picture onset. As already noted in the Introduction, Cheng et al. also found an effect of Name Agreement at around $120 \mathrm{~ms}$ after picture onset, i.e., in the P1 range. Possibly, this early effect resulted from visual properties of the pictures. Given, however, that in the Cheng et al's study the participants performed a covert picture naming task, comparisons with the present study are not straightforward.

Word age of acquisition (AoA) also modulated the duration of the last period of stable electrophysiological pattern (map E) and marginally with our extremely conservative correction criteria of the duration of map D. The duration of these two topographic maps increased for late-acquired words. As reviewed in the Introduction, recent ERP studies converge toward a late locus of AoA effects (see Perret et al., 2014 for recent evidence and discussion). The temporal signature of word Age of Acquisition has been investigated by Laganaro and Perret (2011) and Perret et al. (2014) in picture naming tasks, with ERP topographic analyses. The authors found that word age of acquisition modulated ERPs at $\sim 350-400 \mathrm{~ms}$ after picture presentation (for an overall response time of $\sim 750 \mathrm{~ms}$ ), a time window compatible with lexical-phonological encoding processes. The present results corroborate these findings. Note that according to Indefrey's (2011) estimate, phonological encoding is engaged between 275 and $450 \mathrm{~ms}$ after picture onset. Importantly, however, these estimates were based on mean response latencies of $600 \mathrm{~ms}$. An earlier ERP investigation on the time course of word production comparing different response latencies indicated that lexical (lemma) selection can be lengthened in case of slower production speed (Laganaro et al., 2012), thus delaying phonological encoding (shifting it to the right on the temporal axis); this also seems to be the case in the present data, as mean production latencies are about $800 \mathrm{~ms}$.

Image agreement (IA) modulated the duration of the stable topographic configuration ranging from approximately 380 to $620 \mathrm{~ms}$ after picture onset. Higher image agreement yielded shorter durations of map D. The concept of Image agreement was formalized by Snodgrass and Vanderwart (1980). These authors asked participants to judge the degree to which a picture would correspond to the mental object of that picture's name. Barry et al. (1997, see also Alario et al., 2004) found that the higher these scores, the shorter the naming latencies. The authors hypothesized that image agreement exerts its influence during object recognition. Accordingly, it should modulate ERPs in an early 
time-window associated with pre-linguistic processes. This suggestion was rather intuitive, based on the fact that IA should code the prototypicality of the picture for a given object. Our results are at odds with this interpretation, since IAgr modulated ERPs in the same time-window as AoA and NAgr, i.e., in the time window associated with lexical-phonological processes. This finding questions the association of Image Agreement with pre-linguistic processes, and rather suggests that it refers to the link between the picture and its name. Possibly, IAgr and NAgr reflect the same underlying predictor but are measured differently (as evident from the low correlation between the two measures $(r=0.2)$ and their independent effects on response times and map durations). When asked to estimate Image Agreement, participants are first presented with the name of the picture to rate, and this information likely plays a major role on their ratings. Unlike Name Agreement, however, Image Agreement measures are based on subjective estimated strengths between the picture and the concept. Raters will thus differentiate, for instance, between pictures with a single possible noun, pictures with many nouns among which one is clearly dominant, and pictures with many nouns without a clear favorite. By contrast, Name Agreement measures are based on the objective number of responses provided for a given picture. Consequently, they should not differentiate between the two first categories. It is also worth noting here that the effect of Image agreement, unlike that of NAgr and AoA, does not extend to the following map. This suggests that the mechanisms that are responsible for two consecutive effects for NAgr and AoA do not have a general character.

Interestingly, the duration of the stable electrophysiological activity in the time window ranging from about 180 to about $380 \mathrm{~ms}$ was not affected by any of the variables considered in our study. This period of topographic stability covers a time window which has been previously associated with lexical selection (e.g., Strijkers et al., 2010, see also Indefrey, 2011). The only variable whose influence is thought to originate at least partially during lexical selection is lexical frequency. In the present study, there was no effect of this variable on response times or on any of the periods of topographic stability whatever the lexical frequency measure (spoken or written) considered. This lack of effect cannot be due to the correlation of this variable with other predictors, which are quite low $(r=-0.366$ with image agreement, $r=0.283$ with familiarity and $r=-0.260$ with AoA, all other correlations $<0.2$ ). Moreover, lexical frequency does not affect response latencies or the duration of map $C$, even when entered as the only predictor in the statistical model. In previous studies with picture naming tasks, effects of lexical frequency are reported with factorial designs, where the difference between frequency conditions is maximized (Strijkers et al., 2010) or with continuous measures of lexical frequency in large sets of items. For instance, whereas effects of lexical frequency on naming responses are reported in Alario et al. (2004) with 400 items or in Bonin et al. (2003) with 300 items (400 words), previous studies with 200 items or less did not find any effect of lexical frequency (Bonin et al., 2002; Chalard et al., 2003). In the present study, we used a continuous measure of lexical frequency, with only 100 items and the lack of frequency effect is thus in line with previous findings.
The effects of Name Agreement and of AoA on the two last successive periods of topographic stability raise several crucial points for the architecture of language production models. Although we cannot rule out that these two observations are independent (i.e., Name Agreement and Age of Acquisition may affect each of these periods of stability), their effect on the last period may be determined by the previous one, meaning that the last process started while the previous one was not completed. This issue is closely related to the question of the dynamics of planning processes in speech production. The effect of psycholinguistic variables on two consecutive periods of electrophysiological stability, likely corresponding to two periods of mental information processing (Lehmann et al., 1998; Changeux and Michel, 2004), may be interpreted as cascade activation from one mental process to the other. Hence, although the interpretation of the timecourse of the sequences of periods of topographic stability was framed within the framework of serial word production models (Levelt et al., 1999; Indefrey and Levelt, 2004), the observation that some psycholinguistic variables affect two consecutive periods of stable global electric field suggest interaction (at least in terms of cascading) during these late word planning processes. In the same vein, effects limited to a single stable period (as the effect of visual complexity on map B in the present study) may indicate strictly sequential processes at other planning time-windows. The present study was not designed to explicitly address this question, but the rationale exposed here may be implemented in further investigation to determine if and when interaction is observed in word production.

In addition to documenting important theoretical issues on the time course of word production in picture naming, this research opens up new methodological prospects. So far, previous research on language production using ERPs relied on factorial designs. As underlined by several authors, factorial designs have several drawbacks, including lack of systematic control of potential confounds, and loss of statistical power. By contrast, the methodology used here does not suffer from these downsides and, as such, is particularly valuable for language studies, where the properties of the linguistic materials are salient variables. Moreover, in classical analyses, ERPs are averaged across subjects. Consequently, the statistical models do not provide information about the variance related to the items, and one may question whether their outcomes can truly be generalized across words (e.g., Barr et al., 2013). It is worth noting that several observations in our data suggest that our approach is extremely robust. Firstly, each topographic map revealed by the spatio-temporal segmentation on the grand-average ERPs was present in at least $89 \%$ of the single trials (up to $100 \%$ for some maps). Secondly, the rate of topographic map presence was comparable or higher in single trials than in subjects averaged ERPs. Moreover, the TCT analysis revealed high consistency across trials, except in the short time period ranging from $\sim 150$ to $\sim 180 \mathrm{~ms}$ after picture onset. As previously advocated in other cognitive domains (Tzovara et al., 2012) a high rate of stable electrophysiological map presence licenses a trial by trial approach.

To conclude, the classical mental chronometry approach in cognitive psychology holds that any increase in response latency by a given variable reflects an underlying processing cost. The 
ERP analysis applied here to picture naming data allowed us to associate the cost generated by psycholinguistic variables to the duration of stable electrophysiological processes. This approach identified the time windows at which Visual Complexity, Name Agreement, Age of Acquisition and Image Agreement exert their influence and provided novel and precise information on the time course of word production processes in object picture naming.

\section{ACKNOWLEDGMENTS}

This research was supported by Swiss National Science Foundation grants no. PP001-118969 and PP00P1_140796 to Marina Laganaro.

\section{SUPPLEMENTARY MATERIAL}

The Supplementary Material for this article can be found online at: http://www.frontiersin.org/journal/10.3389/fnins.2014. 00390/abstract

\section{REFERENCES}

Alario, F. X., Costa, A., and Caramazza, A. (2002). Hedging one's bets too much? A reply to Levelt (2002). Lang. Cogn. Process. 17, 673-682. doi: 10.1080/01690960143000461

Alario, F. X., and Ferrand, L. (1999). A set of 400 pictures standardized for French: norms for name agreement, image agreement, familiarity, visual complexity, image variability, and age of acquisition. Behav. Res. Methods Instrum. Comput. 31, 531-552. doi: 10.3758/BF03200732

Alario, F. X., Ferrand, L., Laganaro, M., New, B., Frauenfelder, U. H., and Segui, J. (2004). Predictors of picture naming speed. Behav. Res. Methods Instrum. Comput. 36, 140-155. doi: 10.3758/BF03195559

Aristei, S., Melinger, A., and Abdel Rahman, R. (2011). Electrophysiological chronometry of semantic context effects in language production. J. Cogn. Neurosci. 23, 1567-1586. doi: 10.1162/jocn.2010.21474

Attneave, F. (1957). Physical determinants of the judged complexity of shapes. J. Exp. Psychol. 53, 221-227. doi: 10.1037/h0043921

Baayen, R. H. (2008). Analyzing Linguistic Data: A Practical Introduction to Statistics. Cambridge: Cambridge University Press.

Baayen, R. H. (2010). A real experiment is a factorial experiment? Ment. Lex. 5, 149-157. doi: 10.1075/ml.5.1.06baa

Baayen, R. H., Davidson, D. J., and Bates, D. M. (2008). Mixed-effects modeling with crossed random effects for subjects and items. J. Mem. Lang. 59, 390-412. doi: 10.1016/j.jml.2007.12.005

Bachoud-Lévi, A. C., Dupoux, E., Cohen, L., and Mehler, J. (1998). Where is the length effect? A cross-linguistic study of speech production. J. Mem. Lang. 39, 331-346. doi: 10.1006/jmla.1998.2572

Balling, L. W. (2008). A brief introduction to regression designs and mixed-effects modelling by a recent convert. Copenhagen Stud. Lang. 36, 175-192.

Barr, D., Levy, R., Scheepers, C., and Tily, H. J. (2013). Random effects structure for confirmatory hypothesis testing: keep it maximal. J. Mem. Lang. 68, 255-278 doi: 10.1016/j.jml.2012.11.001

Barry, C., Hirsh, K. W., Johnston, R. A., and Williams, C. L. (2001). Age of acquisition, word frequency, and the locus of repetition priming of picture naming. J. Mem. Lang. 44, 350-375. doi: 10.1006/jmla.2000.2743

Barry, C., Morrison, C. M., and Ellis, A. W. (1997). Naming the Snodgrass and Vanderwart pictures: effects of age of acquisition, frequency, and name agreement. Q. J. Exp. Psychol. 50A, 560-585. doi: 10.1080/783663595

Bates, D. M., and Sarkar, D. (2007). Ime4: Linear Mixed-Effects Models using S4 Classes. R package version 0.9975-12.

Belke, E., Brysbaert, M., Meyer, A. S., and Ghyselinck, M. (2005). Age of acquisition effects in picture naming: evidence for a lexical-semantic competition hypothesis. Cognition 96, B45-B54. doi: 10.1016/j.cognition.2004. 11.006

Blackford, T., Holcomb, P., Grainger, J., and Kuperberg, G. R. (2012). A funny thing happened on the way to articulation: N400 attenuation despite behavioral interference in picture naming. Cognition 123, 84-99. doi: 10.1016/j.cognition.2011.12.007
Bock, K. (1996). Language production: methods and methodologies. Psychon. Bull. Rev. 3, 395-421. doi: 10.3758/BF03214545

Bonin, P., Chalard, M., Méot, A., and Fayol, M. (2002). The determinants of spoken and written picture naming latencies. Br. J. Psychol. 93, 89-114. doi: 10.1348/000712602162463

Bonin, P., Peereman, R., Malardier, N., Mot, A., and Chalard, M. (2003). A new set of 299 pictures for psycholinguistic studies: French norms for name agreement, image agreement, conceptual familiarity, visual complexity, image variability, age of acquisition, and naming latencies. Behav. Res. Methods Instrum. Comput. 35, 158-167. doi: 10.3758/BF03195507

Brunet, D., Murray, M. M., and Michel, C. M. (2011). Spatiotemporal analysis of multichannel EEG: CARTOOL. Comput. Intell. Neurosci. 2011:813870. doi: $10.1155 / 2011 / 813870$

Bürki, A., and Laganaro, M. (2014). Tracking the time course of multi-word noun phrase production with ERPs or on when (and why) cat is faster than the big cat. Front. Psychol. 5:586. doi: 10.3389/fpsyg.2014.00586

Carroll, J. B., and White, M. N. (1973). Age-of-acquisition norms for 220 picturable nouns. J. Verb. Learn. Verb. Behav. 12, 563-576. doi: 10.1016/S00225371(73)80036-2

Chalard, M., and Bonin, P. (2006). Age-of-acquisition effects in picture naming: are they structural and/or semantic in nature? Vis. Cogn. 137, 864-883. doi: 10.1080/13506280544000084

Chalard, M., Bonin, P., Méot, A., and Boyer, B., and Fayol, M. (2003). Objective age-of-acquisition (AoA) norms for a set of 230 object names in French: relationships with other variables used in psycholinguistic experiments, the English data from Morrison et al. (1997) and naming latencies. Eur. J. Cogn. Psychol. 15, 209-245 doi: 10.1080/09541440244000076

Changeux, J. P., and Michel, C. M. (2004). "Mechanisms of neural integration at the brain-scale level. The neuronal workspace and microstate models," in Microcircuits: The Interface between Neurons and Global Brain Function, eds S. Grillner and A. M. Graybiel (Cambridge, MA: MIT Press), 347-370.

Cheng, X., Schafer, G., and Akyürek, E. G. (2010). Name agreement in picture naming: an ERP study. Int. J. Psychophysiol. 76, 130-141. doi: 10.1016/j.ijpsycho.2010.03.003

Cornelissen, K., Laine, M., Renvall, K., Saarinen,T., Martin, N., and Salmelin, R. (2004). Learning new names for new objects: cortical effects as measured by magnetoencephalography. Brain Lang. 89, 617-622. doi: 10.1016/j.bandl.2003.12.007

Costa, A., Strijkers, K., Martin, C., and Thierry, G. (2009). The time course of word retrieval revealed by event-related brain potentials during overt speech. Proc. Natl. Acad. Sci. U.S.A. 106, 21442-21446. doi: 10.1073/pnas.0908 921106

Cuetos, F., Ellis, A. W., and Alvarez, B. (1999). Naming times for the Snodgrass and Vanderwart pictures in Spanish. Behav. Res. Methods Instrum. Comput. 31, 650-658. doi: 10.3758/BF03200741

Damian, M. F., Bowers, J. S., Stadthagen-Gonzalez, H., and Spalek, K. (2010). Does word length affect speech onset latencies in single word production? J. Exp. Psychol. Learn. Mem. Cogn. 36, 892-905. doi: 10.1037/a0019446

Dell, G. S. (1986). A spreading-activation theory of retrieval in sentence production. Psychol. Rev. 93, 283-321. doi: 10.1037/0033-295X.93.3.283

Dell, G. S. (1988). The retrieval of phonological forms in production: tests of predictions from a connectionist model. J. Mem. Lang. 27, 124-142. doi: 10.1016/0749-596X(88)90070-8

Dell, G. S. (1990). Effects of frequency and vocabulary type on phonological speech errors. Lang. Cogn. Process. 5, 313-349. doi: 10.1080/01690969008407066

Dell'Acqua, R., Lotto, L., and Job, R. (2000). Naming times and standardized norms for the Italian PD/DPSS set of 266 pictures: direct comparisons with American, English, French, and Spanish published databases. Behav. Res. Methods Instrum. Comput. 32, 588-615. doi: 10.3758/BF03200832

De Lucia, M., Michel, C. M., Clarke, S., and Murray, M. M. (2007). Single subject EEG analysis based on topographic information. Int. J. Bioelectromagn. 9, $168-171$.

De Lucia, M., Michel, C. M., and Murray, M. M. (2010). Comparing ICA-based and single-trial topographic ERP analyses. Brain Topogr. 27, 119-127. doi: 10.1007/s10548-010-0145-y

Dien, J., Frishkoff, G. A., Cerbone, A., and Tucker, D. M. (2003). Parametric analysis of event-related potentials in semantic comprehension: evidence for parallel brain mechanisms. Cogn. Brain Res. 15, 137-153. doi: 10.1016/S0926-6410(02) 00147-7 
Ellis, A. W., and Morrison, C. M. (1998). Real age-of-acquisition effects in lexical retrieval. J. Exp. Psychol. Learn. Mem. Cogn. 24, 515-523. doi: 10.1037/02787393.24.2.515

Fromkin, V. A. (1971). The non-anomalous nature of anomalous utterances. Language 47, 27-52. doi: 10.2307/412187

Ganushchak, L. Y., Christoffels, I., and Schiller, N. (2011). The use of electroencephalography (EEG) in language production research: a review. Front. Lang. Sci. 2:208. doi: 10.3389/fpsyg.2011.00208

Garrett, M. F. (1980). "Levels of processing in sentence production," in Language Production: Vol. 1. Speech and Talk, ed B. Butterworth (San Diego, CA: Academic Press), 177-220.

Glaser, W. R. (1992). Picture naming. Cognition 42, 61-105. doi: 10.1016/00100277(92)90040-O

Glaser, W. R., and Düngelhoff, F. J. (1984). The time course of picture-word interference. J. Exp. Psychol. Hum. Percept. Perform. 10, 640-654. doi: 10.1037/00961523.10.5.640

Goldstein, H. (1987). Multilevel Models in Educational and Social Research. London: Griffin.

Goldstein, H. (1995). Multilevel Statistical Models. New York, NY: Halstead Press.

Graves, W. W., Grabowski, T. J., Mehta, S., and Gordon, J. K. (2007). A neural signature of phonological access: distinguishing the effects of word frequency from familiarity and length in overt picture naming. J. Cogn. Neurosci. 19, 617-631. doi: 10.1162/jocn.2007.19.4.617

Griffin, Z. M. (2001). Gaze durations during speech reflect word selection and phonological encoding. Cognition 82, B1-B14. doi: 10.1016/S00100277(01)00138-X

Griffin, Z. M., and Bock, K. (1998). Constraint, word frequency, and levels of processing in spoken word production. J. Mem. Lang. 38, 313-338. doi: 10.1006/jmla.1997.2547

Hauk, O., Davis, M. H., Ford, M., Pulvermüller, F., and Marslen-Wilson, W. D. (2006). The time course of visual word recognition as revealed by linear regression analysis of ERP data. Neuroimage 30, 1383-1400. doi: 10.1016/j.neuroimage.2005.11.048

Hernandez, A. E., and Fiebach, C. J. (2006). The brain bases of reading late learned words: evidence from functional MRI. Vis. Cogn. 13, 1027-1043. doi: $10.1080 / 13506280544000183$

Hirsh, K. W., and Funnell, E. (1995). Those old, familiar things: age of acquisition, familiarity and lexical access in progressive aphasia. J. Neurolinguistics 9, 23-32. doi: 10.1016/0911-6044(95)00003-8

Indefrey, P. (2011). The spatial and temporal signatures of word production components: a critical update. Front. Psychol. 2:255. doi: 10.3389/fpsyg.2011.00255

Indefrey, P., and Levelt, W. (2004). The spatial and temporal signatures of word production components. Cognition 92, 101-144. doi: 10.1016/j.cognition.2002.06.001

Janssen, N., Pajtas, P., and Caramazza, A. (2011). A set of 150 pictures with morphologically complex English compound names. Norms for name agreement, familiarity, image agreement and visual complexity. Behav. Res. Methods 43, 478-490. doi: 10.3758/s13428-011-0065-0

Jescheniak, J. D., and Levelt, W. J. M. (1994). Word frequency effects in speech production: retrieval of syntactic information and of phonological form. J. Exp. Psychol. Learn. Mem. Cogn. 20, 824-843. doi: 10.1037/0278-7393.20.4.824

Jescheniak, J. D., Schriefers, H., Garrett, M. F., and Friederici, A. D. (2002). Exploring the activation of semantic and phonological codes during speech planning with event-related brain potentials. J. Cogn. Neurosci. 14, 951-964. doi: 10.1162/089892902760191162

Jescheniak, J. D., Schriefers, H., and Hantsch, A. (2003). Utterance format affects phonological priming in the picture-word task: implications for models of phonological encoding in speech production. J. Exp. Psychol. Hum. Percept. Perform. 29, 441-454. doi: 10.1037/0096-1523.29.2.441

Johnson, C., Paivio, A., and Clark, J. M. (1996). Cognitive components of picture naming. Psychol. Bull. 120, 113-139. doi: 10.1037/0033-2909.120.1.113

Johnston, R. A., and Barry, C. (2005). Age of acquisition effects in the semantic processing of pictures. Mem. Cognit. 33, 905-912. doi: 10.3758/BF03193084

Kan, I. P., and Thompson-Schill, S. L. (2004). Selection from perceptual and conceptual representations. Cogn. Affect. Behav. Neurosci. 4, 466-482. doi: 10.3758/CABN.4.4.466

Kittredge, A. K., Dell, G. S., Verkuilen, J., and Schwartz, M. F. (2008). Where is the effect of frequency in word production? Insights from aphasic picture-naming errors. Cogn. Neuropsychol. 25, 463-492. doi: 10.1080/02643290701674851
Knobel, M., Finkbeiner, M., and Caramazza, A. (2008). The many places of frequency: evidence for a novel locus of the lexical frequency effect in word production. Cogn. Neuropsychol. 25, 256-286. doi: 10.1080/026432907015 02425

Koenig, T., and Melie-García, L. (2010). A method to determine the presence of averaged event-related fields using randomization tests. Brain Topogr. 3, 233-242. doi: 10.1007/s10548-010-0142-1

Kuznetsova, A., Brockhoff, P. B., and Christensen, R. H. B. (2013). lmerTest: Tests for Random and Fixed Effects for Linear Mixed Effect Models (lmer Objects of lme4 Package). R package version 2.0-0. Available online at: http://CRAN.R-project. org/package $=$ lmerTest

Lachman, R., Shaffer, J. P., and Hennrikus, D. (1974). Language and cognition: effects of stimulus codability, name-word frequency, and age of acquisition on lexical reaction time. J. Verb. Learn. Verb. Behav. 13, 613-625. doi: 10.1016/S0022-5371(74)80049-6

Laganaro, M., Morand, S., and Schnider, A. (2009). Time course of evokedpotential changes in different forms of anomia in aphasia. J. Cogn. Neurosci. 21, 1499-1510. doi: 10.1162/jocn.2009.21117

Laganaro, M., and Perret, C. (2011). Comparing electrophysiological correlates of word production in immediate and delayed naming through the analysis of word age of acquisition effects. Brain Topogr. 24, 19-29. doi: 10.1007/s10548010-0162-x

Laganaro, M., Valente, A., and Perret, C. (2012). Time course of word production in fast and slow speakers: a high density ERP topographic study. Neuroimage 59, 3881-3888. doi: 10.1016/j.neuroimage.2011.10.082

Lehmann, D., Strik, W. K., Henggeler, B., Koenig, T., and Koukkou, M. (1998). Brain electric microstates and momentary conscious mind states as building blocks of spontaneous thinking: I. Visual imagery and abstract thoughts. Int. J. Psychophysiol. 29, 1-11. doi: 10.1016/S0167-8760(97)00098-6

Levelt, W. J. M., Praamstra, P., Meyer, A. S., Helenius, P., and Salmelin, R. (1998). An MEG study of picture naming. J. Cogn. Neurosci. 10, 553-567. doi: $10.1162 / 089892998562960$

Levelt, W. J. M., Roelofs, A., and Meyer, A. S. (1999). A theory of lexical access in speech production. Behav. Brain Sci. 21, 1-38.

Martinovic, J., Gruber, T., and Müller, M. M. (2008). Coding of visual object features and feature conjunctions in the human brain. PLOS ONE 3:e3781. doi: 10.1371/journal.pone.0003781

Meyer, A. S., Sleiderink, A., and Levelt, W. J. M. (1998). Viewing and naming objects: Eye movements during noun phrase production. Cognition 66, B25-B33. doi: 10.1016/S0010-0277(98)00009-2

Michel, C. M., Koenig, T., Brandeis, D., and Gianotti, L. R. R. (2009). Electric Neuroimaging. Cambridge: Cambridge University Press. doi: 10.1017/CBO9780511596889

Morrison, C. M., Chappell, T. D., and Ellis, A. W. (1997). Age of acquisition norms for a large set of object names and their relation to adult estimates and other variables. Q. J. Exp. Psychol. 50A, 528-559. doi: 10.1080/027249897392017

Morrison, C. M., and Ellis, A. W. (1995). The roles of word frequency and age of acquisition in word naming and lexical decision. J. Exp. Psychol. Learn. Mem. Cogn. 21, 116-133. doi: 10.1037/0278-7393.21.1.116

Morrison, C. M., Ellis, A. W., and Quinlan, P. T. (1992). Age of acquisition, not word frequency, affects object naming, not object recognition. Mem. Cognit. 20, 705-714. doi: 10.3758/BF03202720

Murray, M. M., Brunet, D., and Michel, C. (2008). Topographic ERP analyses, a step-by-step tutorial review. Brain Topogr. 20, 249-269. doi: 10.1007/s10548008-0054-5

Nakagawa, S., and Schielzeth, H. (2013). A general and simple method for obtaining $R^{2}$ from generalized linear mixed-effects models. Methods Ecol. Evol. 4, 133-142. doi: 10.1111/j.2041-210x.2012.00261.x

Navarrete, E., Basagni, B., Alario, F. X., and Costa, A. (2006). Does word frequency affect lexical selection is speech production? Q. J. Exp. Psychol. 59, 1681-1690. doi: 10.1080/17470210600750558

New, B., Brysbaert, M., Veronis, J., and Pallier, C. (2007). The use of film subtitles to estimate word frequencies. Appl. Psycholinguist. 28, 661-677. doi: 10.1017/S014271640707035X

New, B., Pallier, C., Brysbaert, M., and Ferrand, L. (2004). Lexique 2: a new French lexical database. Behav. Res. Methods Instrum. Comput. 36, 516-524 doi: 10.3758/BF03195598

Oldfield, R. C. (1971). The assessment and analysis of handedness: the Edinburgh inventory. Neuropsychologiai 9, 97-113. doi: 10.1016/0028-3932(71)90067-4 
Paivio, A., Clark, J. M., Digdon, N., and Bons, T. (1989). Referential processing: reciprocity and correlates of naming and imaging. Mem. Cognit. 17, 163-174. doi: 10.3758/BF03197066

Pascual-Marqui, R. D., Michel, C. M., and Lehmann, D. (1995). Segmentation of brain electrical activity into microstates, model estimation and validation. IEEE Trans. Biomed. Eng. 42, 658-665. doi: 10.1109/10.391164

Perret, C., Bonin, P., and Laganaro, M. (2014). Exploring the multiple-level hypothesis of AoA effects in spoken and written picture naming using a topograhic ERP analysis. Brain Lang. 135, 20-31. doi: 10.1016/j.bandl.2014.04.006

Price, C. J. (2012). A review and synthesis of the first 20 years of PET and fMRI studies of heard speech, spoken language and reading. Neuroimage 62, 816-847. doi: 10.1016/j.neuroimage.2012.04.062

R Development Core Team. (2007). R: A Language and Environment for Statistical Computing, Version 2.6.1. Vienna: R Foundation for Statistical Computing. Available online at: http://www.R-project.org/

Rodriguez-Fornells, A., Schmitt, B. M., Kutas, M., and Münte, T. (2002). Electrophysiological estimates of the time course of semantic and phonological encoding during listening and naming. Neuropsychologia 40, 778-787. doi: 10.1016/S0028-3932(01)00188-9

Roelofs, A. (2002). Syllable structure effects turn out to be word length effects: comment on Santiago et al. (2000). Lang. Cogn. Process. 17, 1-13. doi: 10.1080/01690960042000139

Santiago, J., MacKay, D. G., Palma, A., and Rho, C. (2000). Sequential activation processes in producing words and syllables: evidence from picture naming. Lang. Cogn. Process. 15, 1-44. doi: 10.1080/016909600386101

Schendan, H. E., and Kutas, M. (2003). Time course of processes and representations supporting visual object identification and memory. J. Cogn. Neurosci. 15, 111-135. doi: 10.1162/089892903321107864

Schmitt, B. M., Münte, T. F., and Kutas, M. (2000). Electrophysiological estimates of the time course of semantic and phonological encoding during implicit picture naming. Psychophysiology 37, 473-484. doi: 10.1111/1469-8986.3740473

Schriefers, H., Meyer, A. S., and Levelt, W. J. M. (1990). Exploring the time course of lexical access in language production: picture-word interference studies. J. Mem. Lang. 29, 86-102. doi: 10.1016/0749-596X(90)90011-N

Snodgrass, J. G., and Vanderwart, M. (1980). A standardized set of 260 pictures: norms for name agreement, image agreement, familiarity, and visual complexity. J. Exp. Psychol. Hum. Learn. Mem. 6, 174-215. doi: 10.1037/02787393.6.2.174

Snodgrass, J. G., and Yuditsky, T. (1996). Naming times for the Snodgrass and Vanderwart pictures. Behav. Res. Methods Instrum. Comput. 28, 516-536. doi: 10.3758/BF03200540

Strijkers, K., and Costa, A. (2011). Riding the lexical speedway: a critical review on the time course of lexical access in speech production. Front. Psychol. 2:356. doi: 10.3389/fpsyg.2011.00356

Strijkers, K., Costa, A., and Thierry, G. (2010). Tracking lexical access in speech production: electrophysiological correlates of word frequency and cognate effects. Cereb. Cortex 20, 912-928. doi: 10.1093/cercor/bhp153

Szekely, A., D’Amico, S., Devescovi, A., Federmeier, K., Herron, D., Iyer, G., et al. (2005). Timed action and object naming. Cortex 41, 7-26. doi: 10.1016/S00109452(08)70174-6

Thorpe, S., Fize, D., and Marlot, C. (1996). Speed of processing in the human visual system. Nature 381, 520-522. doi: 10.1038/381520a0
Tzovara, A., Murray, M. M., Plomp, G., Herzog, M. H., Michel, C. M., and De Lucia, M. (2012). Decoding stimulus-related information from single-trial EEG responses based on voltage topographies. Pattern Recognit. 45, 2109-2122. doi: 10.1016/j.patcog.2011.04.007

Van Turennout, M., Hagoort, P., and Brown, C. M. (1998). Brain activitity during speaking: from syntax to phonology in 40 milliseconds. Science 280, 572-574. doi: $10.1126 /$ science. 280.5363 .572

Vihla, M., Laine, M., and Salmelin, R. (2006). Cortical dynamics of visual/semantic vs. phonological analysis in picture confrontation. Neuroimage 33, 732-738. doi: 10.1016/j.neuroimage.2006.06.040

Vitevitch, M. S. (2002). The influence of phonological similarity neighborhoods on speech production. J. Exp. Psychol. Learn. Mem. Cogn. 28, 735-747. doi: 10.1037/0278-7393.28.4.735

Vitevitch, M. S., Armbruster, J., and Chu, S. (2004). Sublexical and lexical representations in speech production: effects of phonotactic probability and onset density. J. Exp. Psychol. Learn. Mem. Cogn. 30, 514-529. doi: 10.1037/02787393.30.2.514

Vitevitch, M. S., and Luce, P. A. (2004). A web-based interface to calculate phonotactic probability for words and nonwords in English. Behav. Res. Methods Instrum. Comput. 36, 481-487. doi: 10.3758/BF03195594

Vitevitch, M. S., and Sommers, M. S. (2003). The facilitative influence of phonological similarity and neighborhood frequency in speech production in younger and older adults. Mem. Cogn. 31, 491-504. doi: 10.3758/BF03196091

Vitkovitch, M., and Tyrrell, L. (1995). Sources of disagreement in object naming. Q. J. Exp. Psychol. 48A, 822-848. doi: 10.1080/14640749508401419

Wilson, S. M., Isenberg, A. L., and Hickok, G. (2009). Neural correlates of word production stages delineated by parametric modulation of psycholinguistic variables. Hum. Brain Mapp. 30, 3596-3608. doi: 10.1002/hbm.20782

Yarkoni, T., Balota, D. A., and Yap, M. J. (2008). Moving beyond Coltheart's N: a new measure of orthographic similarity. Psychon. Bull. Rev. 15, 971-979. doi: 10.3758/PBR.15.5.971

Zhang, Q., and Damian, M. F. (2009). The time course of segment and tone encoding in Chinese spoken production: an event-related potential study. Neuroscience 163, 252-265. doi: 10.1016/j.neuroscience.2009.06.015

Conflict of Interest Statement: The authors declare that the research was conducted in the absence of any commercial or financial relationships that could be construed as a potential conflict of interest.

Received: 31 May 2014; accepted: 14 November 2014; published online: 04 December 2014.

Citation: Valente A, Bürki A and Laganaro M (2014) ERP correlates of word production predictors in picture naming: a trial by trial multiple regression analysis from stimulus onset to response. Front. Neurosci. 8:390. doi: 10.3389/fnins.2014.00390

This article was submitted to Brain Imaging Methods, a section of the journal Frontiers in Neuroscience.

Copyright (c) 2014 Valente, Bürki and Laganaro. This is an open-access article distributed under the terms of the Creative Commons Attribution License (CC BY). The use, distribution or reproduction in other forums is permitted, provided the original author(s) or licensor are credited and that the original publication in this journal is cited, in accordance with accepted academic practice. No use, distribution or reproduction is permitted which does not comply with these terms. 